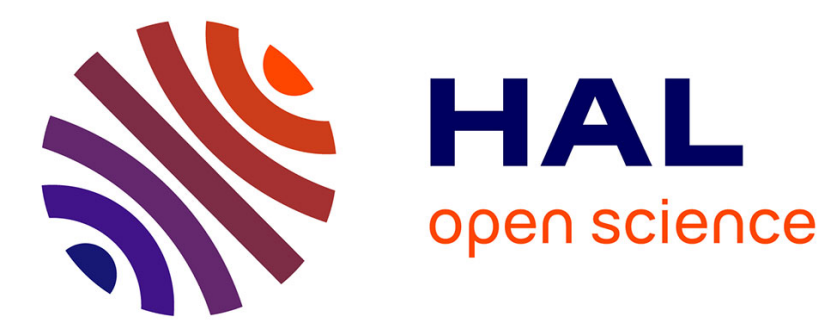

\title{
Effects of miniature transponders on physiological stress, locomotor activity, growth and survival in small lizards
} Jean-François Le Galliard, Matthieu Paquet, Zorica Pantelic, Samuel Perret

\section{To cite this version:}

Jean-François Le Galliard, Matthieu Paquet, Zorica Pantelic, Samuel Perret. Effects of miniature transponders on physiological stress, locomotor activity, growth and survival in small lizards. Amphibia-Reptilia, 2011, 32 (2), pp.177-183. 10.1163/017353710X552371 . hal-00858122

\section{HAL Id: hal-00858122 \\ https://hal.science/hal-00858122}

Submitted on 4 Mar 2014

HAL is a multi-disciplinary open access archive for the deposit and dissemination of scientific research documents, whether they are published or not. The documents may come from teaching and research institutions in France or abroad, or from public or private research centers.
L'archive ouverte pluridisciplinaire HAL, est destinée au dépôt et à la diffusion de documents scientifiques de niveau recherche, publiés ou non, émanant des établissements d'enseignement et de recherche français ou étrangers, des laboratoires publics ou privés. 


\title{
Effects of miniature transponders on physiological stress, locomotor activity, growth and survival in small lizards
}

\author{
Jean-François Le Galliard ${ }^{1,2, *}$, Matthieu Paquet ${ }^{1}$, Zorica Pantelic $^{3}$, Samuel Perret ${ }^{2}$
}

\begin{abstract}
The marking of small animals for long-term ecological studies requires unambiguous and permanent techniques that cause minimal harm. Toe-clipping is frequently used to identify small lizards in the field, but it has been suggested that passive integrated transponders (PIT tags) should be preferred. Here, we evaluate the costs and benefits of new miniature PIT tags to mark the common lizard (Zootoca vivipara). Our protocol enables permanent marking of lizards as small as 1.3 grams with maximal implantation success in the abdominal cavity. Tag injection caused no observable increase in plasma corticosterone levels over five days and no negative effects on long-term growth and survival. However, tag injection had negative effects on locomotor activity during at least 7 days, possibly implying pain. Continuous research to improve tag implantation is needed because negative effects may be caused by anaesthesia and injection rather the tag retention itself. This study demonstrates the utility of combining physiological, behavioural and life history measurements to assess marking stress and pain in animals.
\end{abstract}

Keywords: corticosterone, locomotion, pain, permanent marking, physiological stress.

\section{Introduction}

Individual based data are crucial to assess the population characteristics of wild vertebrates (Dunham et al., 1988). In small species of reptiles and amphibians and most juvenile forms, the best methods to permanently mark individuals are still controversial (e.g., Funk et al., 2005; Langkilde and Shine, 2006; Parris et al., 2010). In particular, because of their small size, many lizard species are difficult to mark permanently using techniques that (i) avoid undue pain and stress, (ii) have no effect on survivorship or growth, (iii) allow fast and error-free individual identification and (iv) produce marks that are not easily lost (reviewed in Ferner, 2007). Small lizards can be identified individually by nonor weakly invasive techniques such as photo-

1 - CNRS/UPMC/ENS, UMR 7625, Laboratoire Ecologie \& Evolution, Université Pierre et Marie Curie, 7 Quai St. Bernard, 75005, Paris, France

2 - CNRS, UMS 3194, CEREEP-Ecotron Ile-de-France, Ecole Normale Supérieure, 78 rue du Château, 77140 St Pierre les Nemours

3 - Nonatec, Lutronic International, 1 rue de L'Industrie, L4830 Rodange, Luxembourg

* Corresponding author; e-mail:

galliard@biologie.ens.fr graphic identification, painting, or bead-tagging (e.g., Perera and Perez-Mellado, 2004; Johnson, 2005). Unfortunately, these techniques do not meet some of the requirements of long-term ecological studies: tags can be lost and identification is usually impossible after a moult, the number of individuals that can be marked is lower than the requirements of long-term studies, and colour marks may increase conspicuousness to predators (Ferner, 2007).

These difficulties explain why, at present, more invasive methods (scale clipping, heat branding and toe clipping) are considered as the most practical and reliable techniques for marking most lizard species (reviewed in Dunham et al., 1988; Ferner, 2007). Being preferred for its efficiency and practicality with the smallest species, toe-clipping has been the subject of some experiments to evaluate its negative effects. Toe-clipping inflicts various degrees of pain and stress, and toes are important for locomotion (e.g., Carothers, 1986; Ferner, 2007). Yet, several studies have shown that appropriate toe-clipping protocols have few permanent effects on the locomotion, growth and/or survival of lizards (Huey et al., 1990; Dodd, 1993; Borges-Landaez and Shine, 2003; Paulissen and 
Meyer, 2000) and cause minimal physiological stress (Langkilde and Shine, 2006), while two studies found significant negative effects in arboreal and climbing species (Rodda et al., 1998; Bloch and Irschick, 2005). Despite these results, animal ethic committees suggest that passive integrated transponders (PIT tags) should be preferred to toe clipping on grounds that this technique is more humane, less harmful, and more reliable (Camper and Dixon, 1988; Langkilde and Shine, 2006). In general, preference should go towards marking methods that combine maximal efficiency and minimal suffering (HACC, 2004). In lizards, PIT tags can be injected subcutaneously or intracoelomically (i.e., in the body cavity), and they usually have a high implantation success, a low rate of reading mistakes, and a good durability (Camper and Dixon, 1988; Germano and Williams, 1993). However, PIT tags are difficult to inject in small individuals. Furthermore, one recent laboratory study demonstrated that PIT tag injection can induce a prolonged elevation of physiological stress in small lizards (Langkilde and Shine, 2006). Thus, the question of the long-term negative effects of this technique remains to be investigated prior to a more widespread use.

We studied PIT-tag efficiency and negative effects in the common lizard, Zootoca vivipara, a ground dwelling European species subject to ecological studies where we routinely use toe-clipping to mark individuals (e.g., Le Galliard et al., 2010). During this experiment, we compared experimental groups of male lizards injected subcutaneously in the belly or intracoelomically with control, unmanipulated lizards. We evaluated tag loss and consequences of marking for plasma corticosterone levels and locomotor behaviour during less than a week, and for growth and survival until 300 days after the injection. To cope with the small size (40$60 \mathrm{~mm}$ snout-vent length) and mass (1-5 g) of our study animals, we used miniature chips (6 by $1 \mathrm{~mm}$ ) that are smaller than most PIT tags available on the market (Gibbons, 2004).
Following on the terminology and framework of Carstens and Moberg (2000), we combined physiological, behavioural and life history approaches to assess marking stress (defined as the physiological response to cope with a marking protocol), pain (defined as an unpleasant emotional state due to marking) and distress (a more severe stress situation where an animal's growth, reproduction and survival is challenged), respectively. First, we measured plasma levels of a glucocorticoid (corticosterone) before and after the implantation. An increase in corticosterone levels is clearly associated with stress in most vertebrates, including the common lizard (Dauphin-Villemant and Xavier, 1987; Wingfield and Ramenofsky, 1999). We measured corticosterone five days after implantation to evaluate sustained stress like in a previous study by Langkilde and Shine (2006) rather than immediate responses to implantation and handling. Second, we investigated effects of implantation on activity and locomotion behaviours within a week after implantation. A previous study of the common lizard has shown that a corticosterone increase can be associated with less basking and resting activities, and more walking and scratching behaviours (de Fraipont et al., 2000). Thus, if tag implantation causes a prolonged physiological stress, we expect significant increases in locomotor activity after marking. On the other hand, if marking causes only pain, animals should be less mobile and active after implantation. Indeed reduced activity is often associated with suffering in laboratory animals (Carstens and Moberg, 2000). Third, we tested for differences in mass changes and survival until almost a year after the tag implantation.

\section{Animals and methods}

Study animals and data collection

Experiments were conducted from July 2008 to April 2009 with 23 yearling and adult male common lizards maintained in a breeding facility in ad libitum conditions (see Le Galliard et al., 2003 for more information). Animals were acclimated to captivity for more than a month and had therefore 
low basal levels of corticosterone before starting the experiment (see below). Lizards were selected to cover a range of variation in body mass (range $=1.30-4.90 \mathrm{~g}$ ) but yearlings less than $1 \mathrm{~g}$ and newborns (mass $=200-300 \mathrm{mg}$ ) were excluded. These animals could not be reasonably fit with our PIT tag due to their small size (pers. obs.). All study animals had been marked in previous years by toe-clipping, thus enabling their unambiguous identification even after a tag loss. At day 0 (July 29, 2008), individuals were weighed to the nearest $\mathrm{mg}$. In addition, we recorded the behavioural activity of each individual using a neutral arena test. The neutral arena consisted of a wood box $(50 \mathrm{~cm} \times 18 \mathrm{~cm})$ littered with clean sand and warmed at two edges with a bulb $(25 \mathrm{~W})$ to create an optimal thermal gradient inside the box $\left(25-35^{\circ} \mathrm{C}\right)$. Lizards were filmed from above during $20 \mathrm{~min}$ after an acclimation period of $20 \mathrm{~min}$; therefore, the neutral arena test does not measure exploration per se since the lizard is acclimated prior to the recordings. We checked each trial for abnormal behaviours (shivering, irregular breathing, or severely reduced locomotor ability) and scored each individual for total distance travelled during the trial and mean movement speed using ImageJ software (http://rsbweb.nih.gov/ij/). We also analysed each trial for the duration of four behaviours (walking on the ground, basking below a bulb, resting on the ground and scratching the walls in an apparent attempt to escape) using the software EthoLog (Ottoni, 2000). Distance travelled during the trial is correlated with the proportion of time spent walking on the ground and is highly repeatable (Le Galliard and Paquet, unpub. data).

At day 1 and prior to manipulation, all animals weighing more than $2 \mathrm{~g}$ were blood sampled for analyses of plasma corticosterone levels $(n=18)$. Blood samples $(40-80 \mu 1$ whole blood) were collected from the post-orbital sinus using $50 \mu \mathrm{l}$ microhematocrit tubes. All samples were collected within $3 \mathrm{~min}$ of removal of an animal from its home cage and between 10:00 and 12:00 $\mathrm{h}$ in order to avoid a handling-induced increase and reduce variability due to diurnal rhythms in the secretion of corticosterone (DauphinVillemant and Xavier, 1987). Blood samples were centrifuged and harvested plasma was stored at $-20^{\circ} \mathrm{C}$. After all blood samplings were completed and a rest period of 3-4 hours, lizards were allocated randomly in each of three experimental groups: a control group of animals was not manipulated and received no transponder injection (hereafter called CONT group, $n=7$ ), a treatment group of animals was injected with transponders subcutaneously (SUB group, $n=8$ ), and a treatment group of animals was injected intracoelomically with transponders (INT group, $n=8$ ). There were no initial differences in size, mass or behaviour between treatments (ANOVA, all $p>0.05$ ). Transponders were injected from 13:00 to 15:00 following a standard procedure (see next section). Control animals were not manipulated when other animals were injected with transponders to measure total effects of our protocol, which includes handling, cold anaesthesia, implantation, and tag retention.

After manipulation at day 1 , lizards were checked visually for recovery from the manipulation (including signs of inflammation, wounding and infection), weighed at days 3 , 5,7 and 9 , and recorded for their behavioural activity at days
2 and 7. The same lizards blood sampled on day 1 were also sampled on day 5 . We did not sample blood immediately after tag implantation because we already know than handling increases corticosterone levels within hours (DauphinVillemant and Xavier, 1987; Langkilde and Shine, 2006) and we wanted to evaluate sustained stress levels like in the previous study by Langkilde and Shine (2006). At day 9, animals were released by groups of 2 individuals in each of 12 outdoor cages. Outdoor cages consisted of a natural habitat $(2 \times 1 \times 0.5 \mathrm{~m}, \mathrm{~L} \times \mathrm{W} \times \mathrm{D})$ enclosed with plastic walls buried deep into the ground and protected on top by a lizard-proof net to avoid potential escapes and avian predation. Outdoor cages were provisioned with wood and rocks as shelter and permanent access to water. Prior to the winter, animals were recaptured, checked visually for healing from tag implantation and weighed at day 19 (July 18) and day 40 (September 8). After overwintering, animals were recaptured, checked for survival and measured for body mass at day 259 (April 9, 2009) and day 285 (May 5, 2009).

\section{Tag technology and injection}

We used the miniature RFID tag manufactured by Nonatec $^{\text {TM }}$ (NXP MF0 IC UI, 6 by $1 \mathrm{~mm}$, www.nonatec. net) and operating at a frequency of $13.56 \mathrm{Mhz}$. We chose to inject all animals around the left posterior ventral part of the abdominal cavity (Germano and Williams, 1993). Prior to injection, all equipment was disinfected and animals were cold anesthetised by storing them during approximately $1 \mathrm{~h}$ in a freezer kept at $3-5^{\circ} \mathrm{C}$. The injection site was cleaned with a diluted solution of betadine and the animal was positioned dorsally. The tag was injected below a ventral scale with a syringe (diameter $1.2 \mathrm{~mm}, 18$ gauge). The syringe was inserted sub-cutaneously in the SUB group where the tag was forced below the skin. The syringe was used to incise the skin in the INT group and the tag was then manually injected inside the abdominal cavity with forceps. After the tag was inserted, we applied a gentle compression around the injection site to avoid bleeding and kept the manipulated lizard in a clean terrarium from 15:00 to 18:00. Animals were then treated with a topical application of an antiseptic spray on the implantation site (chlorexidine $2 \%$, RONT $^{\circledR}$ production, France) and returned to their terraria.

\section{Corticosterone assays}

We measured plasma corticosterone concentrations (CORT) in each blood sample using Enzyme ImmunoAssay (EIA) kit (AC-14F1, IDS, Boldon, UK) following the manufacturer's protocol. Given the range of variation in CORT observed in the common lizard (Meylan et al., 2003), all plasma samples were diluted 1:10 with assay dilutant and standard curves were calibrated with standard samples ranging from $0.01 \mathrm{ng} / \mathrm{ml}$ to $188 \mathrm{ng} / \mathrm{ml}$ equivalent CORT. Intraassay repeatability for the standard samples was very strong (intra-class correlation coefficient of absorbance data, $r=$ 0.99). 


\section{Results}

Handling of animals and laboratory equipments as well as injections of miniature tags proved feasible for two experienced persons. Despite the modest anaesthesia resulting from exposure to cold, animals were calm during injection, which lasted between 2 to 5 min. Bleeding was observed in 7 out of the 16 treated animals but it stopped following a compression or after less than an hour of rest. Localised wounding (necrosis of tissue and scales) was also observed around the injection site for 9 animals out the 16 treated lizards, but wounding was very restricted $(<1 \mathrm{~mm})$ in 7 animals and only obvious in 2 animals (corresponding to 3-4 ventral scales). No animal showed signs of postmanipulation infection or severe inflammation. All animals retained their tags from day 1 to day 7 but 3 animals from the SUB group lost their tags at day 19 following a moult. New tags were gently reinserted in the same subcutaneous position and no tag was subsequently lost during the study. Note that this replacement would not be feasible in the field.

We did not observe abnormal behaviour (shivering, irregular breathing, or severe reduction of locomotor ability) during the behavioural tests but the treatments induced a significant change in locomotor activity compared to pre-manipulation levels. These changes were evident both for total distance travelled (ANOVA of treatment effects for change from before to after manipulation, day $2: F_{2,20}=$ $4.16, p=0.03$, day $7: F_{2,20}=4.46, p=0.02$ ) and movement speed at day 2 (ANOVA of treatment effects for change from before to after manipulation, day 2: $F_{2,20}=6.49, p=0.007$, day 7: $F_{2,20}=2.71, p=0.09$; see fig. $1 \mathrm{~A}$ ). Movement distance travelled on day 2 was significantly reduced in the INT group compared to the CONT group $(t=-2.83$, df $=20, p=$ $0.01)$ but only marginally reduced in the SUB group $(t=-2.00$, df $=20, p=0.06)$. On day 7 , i.e., six days following the manipulation, movement distance was significantly reduced in both the INT and SUB groups compared to the
A

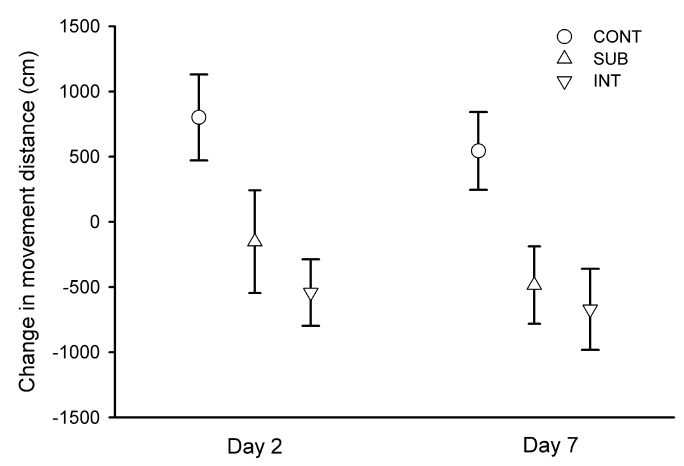

B

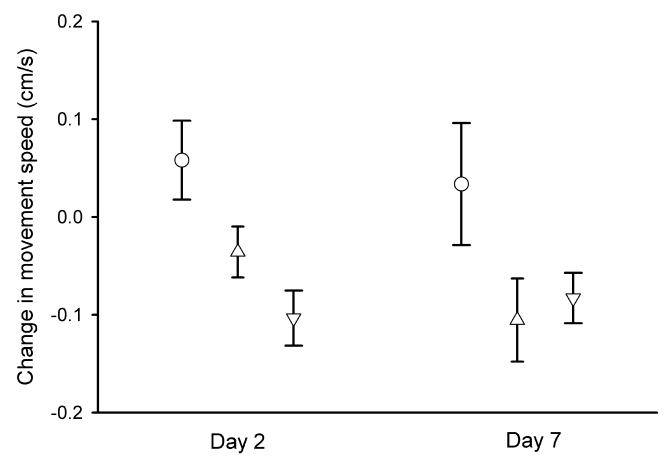

Figure 1. Change in locomotor activity from before to after the manipulation period in control (CONT), sub-cutaneous (SUB) and intra-abdominal (INT) groups. Data show mean $( \pm \mathrm{SE})$ change of measurements done 2 days and 7 days after the manipulation for total distance travelled during the behavioural trial (A) and movement speed (B). See text for statistical details.

CONT group (respectively, $t=-2.8$, df $=20$, $p=0.01 ; t=-2.37, \mathrm{df}=20, p=0.03)$. Similar qualitative results were obtained for movement speed (see fig. 1B). The other behaviours (resting, scratching, and basking) did not differ between treatment and control groups (ANOVA of treatment effects for change from before to after manipulation, all $p>0.05$ ).

The CORT levels ranged for all lizards from $4.74 \mathrm{ng} / \mathrm{ml}$ to $86.51 \mathrm{ng} / \mathrm{ml}$ (mean $=25.22 \pm$ $2.87 \mathrm{SE} \mathrm{ng} / \mathrm{ml}$ ). Changes in CORT from before to five days after manipulation were not affected by the treatment $\left(F_{2,14}=1.66, p=\right.$ 0.22; CONT: $+4.40 \mathrm{ng} / \mathrm{ml} \pm 6.17 \mathrm{SE}, \mathrm{SUB}$ : $+5.05 \mathrm{ng} / \mathrm{ml} \pm 6.70 \mathrm{SE}, \mathrm{INT}:-8.99 \mathrm{ng} / \mathrm{ml} \pm$ $5.50 \mathrm{SE})$. CORT levels were significantly correlated between measurements (Pearson's prod- 
uct moment correlation, $r=0.62, p=$ 0.006). The treatment also had no effect on mass change prior to the winter (change from premanipulation levels to late summer, $F_{2,19}=$ $0.42, p=0.66, n=22$ ), mass change during the winter and early spring (change from late summer to post-wintering levels, $F_{2,15}=2.59$, $p=0.11, n=18$ ) and mass change during spring (change from to post-wintering to late May, $F_{2,10}=0.02, p=0.98, n=13$ ). A repeated measure analysis of variance including all observations of body mass yielded a similar result (not shown). Summer and overwinter mortality was low ( 5 dead animals out of 23 released animals) and some additional mortality was observed during spring (5 additional dead animals). Survival from the start to the end of the experiment was not influenced by treatment (Fisher exact test, $p=0.33$; CONT: 4 survivors out of 7 lizards, SUB: 3 out of 8, INT: 6 out of 8 ).

\section{Discussion}

Our experiment evaluates the efficiency and negative effects of a marking method involving handling, cold anaesthesia, and injection of miniature PIT-tags ( 6 by $1 \mathrm{~mm}$ ) designed for small lizards of a minimum body size of ca. 40 to $50 \mathrm{~mm}$ snout-vent length and a minimum weight of ca. 1 to 2 grams. Previous studies had used larger tags ( $>12$ by $2 \mathrm{~mm}$ ) that could not be reasonably fitted to these animals. Thus, our miniature tags extend importantly the range of body size and therefore the number of lizard species that can be marked with passive integrated transponders. All tags were injected in a ventral position, but we found more implantation success following injection in the intra-abdominal cavity (success rate $=$ $100 \%$ ) than with a subcutaneous injection (success rate $=62 \%$ ). Tag loss from subcutaneous injection was associated with a moult occurring approximately 19 days after implantation. These results are in line with those of a study of the lizard Gambelia sila involving a much larger sample size (Germano and Williams, 1993) and suggest that intra-abdominal injection should be preferred in lizards. Application of a surgical glue around the injection site is sometimes advocated to favour healing and decrease tag loss (HACC, 2004). However, we have found this to instead slow down healing in some pilot studies (pers. obs.).

We did not quantify post-manipulation pain and trauma within minutes or hours of implantation, but we found some effects on male behaviour within days after the manipulation. Males injected with a PIT-tag intracoelomically or subcutaneously displayed less locomotor behaviours and moved more slowly for periods ranging at least from 2 to 7 days after the manipulation. These changes were more obvious after 2 days for animals injected intracoelomically though the two treatment groups did not differ significantly in their behaviours (see fig. 1). Previous studies indicated that an increase in locomotor activity is associated with physiological stress in the common lizard (de Fraipont et al., 2000), but our experiment found no effects of marking on plasma corticosterone levels. Hormonal levels of male common lizards (mean $=$ $25 \mathrm{ng} / \mathrm{ml}$ ) were low compared to typical stress levels in the laboratory (e.g., $90 \mathrm{ng} / \mathrm{ml}$, see Dauphin-Villemant and Xavier, 1987) and were also consistent across measurements within the same individual. These results differ from those of Langkilde and Shine (2006) who found that tag injection causes a prolonged elevation of plasma corcicosterone levels after 14 days in the Australian scincid, Eulamprus heatwolei. In this study, physiological changes were obvious in female scincids but male corticosterone levels did not change with the manipulation. We did not investigate the impact of tag implantation on female $Z$. vivipara and this should be examined in future studies. The study of Langkilde and Shine (2006) and ours emphasize the complex relationships between hormonal stress and marking stress. Such variation in hormonal stress responses has already been observed across species, within species be- 
tween age and sex classes, and also within the same individual across seasons (Wingfield and Ramenofsky, 1999; Moore and Jessops, 2003). Therefore, studies that focus only on physiological measurements to assess marking stress should be considered with some caution.

The lower locomotor activity of lizards injected with a transponder could result from a post-injection trauma and/or from a constraint due to tag retention, and is therefore probably indicative of a pain response (Carstens and Moberg, 2000). Alternative procedures than cold anaesthesia are available to provide animals with sedation and surgical anaesthesia and therefore to diminish the pain caused by tag injection. Such techniques certainly warrant further investigations, but are less feasible to mark animals in the field. Recently, our group has tested a variety of injectable and inhalant anaesthetic, and found that isoflurane (Forene, $\mathrm{Ab}$ bott) is the most successful for adults (Meylan and Bleu, pers. comm.). Irrespective of their causes, the observed behavioural changes could lead to some negative effects on mass growth and survival because foraging is tightly linked with locomotor behaviour in actively foraging lizards (e.g., Lorenzon et al., 1999). Yet, we found no effects of tag injection for mass growth and annual survival. This result must be interpreted with some caution because the low sample size of this study leads to a small statistical power and any small effects would not be detected. No other study had tested for effects of transponder injection on growth and survival in lizards, but Keck (1994) and Jemison et al. (1995) also found no effect on growth and recapture rates for snakes. Generally, there appears to be only mild effects of transponder injection for condition, growth, survival and reproduction of animals (Gibbons, 2004), but future studies with larger sample sizes are needed.

In conclusion, our study demonstrates the applicability of miniature transponder technology to mark lizards as small as 1-2 grams. Tag injection decreased the locomotor activity of animals during at least a week, but had no sig- nificant effects on physiological stress after five days and did not impair mass growth and annual survival. However, this technique is more time consuming, more expensive, and more difficult to perform than toe clipping, and tag loss can occur if the tag is not injected in the abdominal cavity. Also, marking smaller individuals, especially newborns, is clearly not feasible. Continuous research to improve implantation of transponders in small animals is needed. In general, the evaluation of stress and pain is a complex issue, and our study demonstrates the utility of combining physiological, behavioural and life history measurements to assess marking stress in lizards. Indeed, evaluations of effects based on behavioural data provided a different picture than standard physiological and life history tests.

Acknowledgements. This research has been supported by the Centre National de la Recherche Scientifique (CNRS) and an ANR grant (07-JCJC-0120) to Jean-François Le Galliard. We thank C. Haussy and S. Meylan for assistance with the hormonal assays, M. Mugabo for help in the laboratory, and S. Meylan for critical review of an earlier version. Experimentations at the CEREEP breeding facility (www.foljuif.ens.fr) were done in accordance with French and European regulation on animal experimentation and welfare. Experimental protocols were approved by the Regional Ethics Committee in Animal Experiment $\mathrm{N}^{\circ} 3$ of Ilede-France region (application p3/2008/040).

\section{References}

Bloch, N., Irschick, D.J. (2005): Toe-clipping dramatically reduces clinging performance in a pad-bearing lizard (Anolis carolinensis). J. Herpetol. 39: 288-293.

Borges-Landaez, P.A., Shine, R. (2003): Influence of toeclipping on running speed in Eulampus quoyii, an Australian scincid lizard. J. Herpetol. 37: 592-595.

Camper, J.D., Dixon, J.R. (1988): Evaluation of a microchip marking system for amphibians and reptiles. In: Texas Parks and Wildlife Department, Research Publication, p. 1-22.

Carothers, J. (1986): An experimental confirmation of morphological adaptation: toe fringes in the sanddwelling lizard Uma scoparia. Evolution 40: 871-874.

Carstens, E., Moberg, G.P. (2000): Recognizing pain and distress in laboratory animals. Ilar Journal 41: 62-71.

Dauphin-Villemant, C., Xavier, F. (1987): Nycthemeral variations of plasma corticosteroids in captive female Lacerta vivipara Jacquin: influence of stress and reproductive state. Gen. Comp. Endocrinol. 67: 292-302. 
de Fraipont, M., Clobert, J., John-Alder, H., Meylan, S. (2000): Increased pre-natal maternal corticosterone promotes philopatry of offspring in common lizards Lacerta vivipara. J. Anim. Ecol. 69: 404-413.

Dodd, C.K. (1993): The effects of toe-clipping on sprint performance of the lizard Cnemidophorus sexlineatus. J. Herpetol. 27: 209-213.

Dunham, A.E., Morin, P.J., Wilbur, H.M. (1988): Methods for the study of reptile populations. In: Biology of the Reptilia, p. 330-386. Gans, C., Huey, R.B., Eds, New York, NY, Alan R. Liss.

Ferner, J.W. (2007): A Review of Marking and Individual Recognition Techniques for Amphibians and Reptiles. Herpetological Circular, Vol. 35. Salt Lake City, UT, Society for the Study of Amphibians and Reptiles.

Funk, W.C., Donnelly, M.A., Lips, K.R. (2005): Alternative views of amphibian toe-clipping. Nature 433: 193.

Germano, D.J., Williams, D.F. (1993): Field evaluation of using passive integrated transponder (PIT) tags to permanently mark lizards. Herpetol. Rev. 24: 54-56.

Gibbons, J.W. (2004): PIT tagging: simple technology at its best. Bioscience 54: 447-454.

HACC (2004): Guidelines for Use of Live Amphibians and Reptiles in Field and Laboratory Research. American Society of Ichthyologists and Herpetologists, Herpetological Animal Care and Use Committee.

Huey, R.B., Dunham, A.E., Overall, K.L., Newman, R.A. (1990): Variation in locomotor performance in demographically known populations of the lizard Sceloporus merriami. Physiol. Zool. 63: 845-872.

Jemison, S.C., Bishop, L.A., May, P.G., Farrell, T.M. (1995): The impact of pit-tags on growth and movement of the rattlesnake Sistrurus miliarius. J. Herpetol. 29: 129-132.

Johnson, M.A. (2005): A new method of temporarily marking lizards. Herpetol. Rev. 36: 277-279.

Keck, M.B. (1994): Test for detrimental effects of pit tags in neonatal snakes. Copeia 1994: 226-228.

Langkilde, T., Shine, R. (2006): How much stress do researchers inflict on their study animals? A case study using a scincid lizard, Eulamprus heatwolei. J. Exp. Biol. 209: 1035-1043.
Le Galliard, J.-F., Le Bris, M., Clobert, J. (2003): Timing of locomotor impairment and shift in thermal preferences during gravidity in a viviparous lizard. Funct. Ecol. 17: 877-885.

Le Galliard, J.-F., Marquis, O., Massot, M. (2010): Cohort variation, climate effects and population dynamics in a short-lived lizard. J. Anim. Ecol. 79: 1296-307.

Lorenzon, P., Clobert, J., Oppliger, A., John-Alder, H.B. (1999): Effect of water constraint on growth rate, activity and body temperature of yearling common lizard (Lacerta vivipara). Oecologia 118: 423-430.

Meylan, S., Dufty, A.J., Clobert, J. (2003): The effect of transdermal corticosterone application on plasma corticosterone levels in pregnant Lacerta vivipara. Comparative Biochemistry and Physiology Part A 134: 497-503.

Moore, I.T., Jessops, T.S. (2003): Stress, reproduction, and adrenocortical modulation in amphibians and reptiles. Horm. Behav. 43: 39-47.

Ottoni, E.B. (2000): EthoLog 2.2 - a tool for the transcription and timing of behavior observation sessions. Behavior Research Methods, Instruments, and Computers 32: 446-449.

Parris, K.M., McCall, S.C., McCarthy, M.A., Minteer, B.A., Steele, K., Bekessy, S., Medvecky, F. (2010): Assessing ethical trade-offs in ecological field studies. J. Appl. Ecol. 47: 227-234.

Paulissen, M.A., Meyer, H.A. (2000): The effect of toeclipping on the gecko Hemidactylus turcicus. J. Herpetol. 34: 282-285.

Perera, A., Perez-Mellado, V. (2004): Photographic identification as a non-invasive method for lacertid lizards. Herpetol. Rev. 35: 349-350.

Rodda, G.H., Bock, B.C., Burghardt, G.M., Rand, A.S. (1998): Techniques for identifying individual lizards at a distance reveal influence of handling. Copeia 1988: 905913.

Wingfield, J.C., Ramenofsky, M. (1999): Hormones and the behavioral ecology of stress. In: Stress Physiology in Animals, p. 1-51. Palm, P.H.M., Ed., Sheffield, Sheffield Academic Press.

Received: October 18, 2010. Accepted: December 15, 2010. 